\section{(6) OPEN ACCESS}

\title{
Maternal alcohol intake prior to and during pregnancy and risk of adverse birth outcomes: evidence from a British cohort
}

\author{
Camilla Nykjaer, ${ }^{1}$ Nisreen A Alwan, ${ }^{1}$ Darren C Greenwood, ${ }^{2}$ Nigel A B Simpson, ${ }^{3}$ \\ Alastair W M Hay, ${ }^{4}$ Kay L M White, ${ }^{4}$ Janet E Cade ${ }^{1}$
}

${ }^{1}$ Nutritional Epidemiology Group, School of Food Science and Nutrition, University of Leeds, Leeds, UK

${ }^{2}$ Division of Biostatistics, Centre for Epidemiology and Biostatistics, University of Leeds, Leeds, UK

${ }^{3}$ Department of Obstetrics and Gynaecology, University of Leeds, Leeds, UK

${ }^{4}$ Epidemiology, LIGHT Institute, University of Leeds, Leeds, UK

\section{Correspondence to} Camilla Nykjaer Nutritional Epidemiology Group, School of Food Science and Nutrition, University of Leeds, Leeds LS2 9JT, UK; c.nykjaer@leeds.ac.uk

Received 4 June 2013 Revised 10 December 2013 Accepted 23 December 2013 Published Online First 10 March 2014

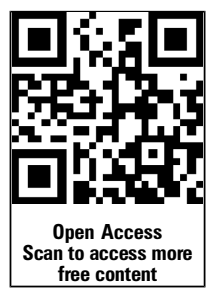

CrossMark

To cite: Nykjaer $C$, Alwan NA, Greenwood DC, et al. J Epidemiol Community Health 2014;68:542-549.

\section{ABSTRACT}

Background Evidence is conflicting regarding the relationship between low maternal alcohol consumption and birth outcomes. This paper aimed to investigate the association between alcohol intake before and during pregnancy with birth weight and gestational age and to examine the effect of timing of exposure.

Methods A prospective cohort in Leeds, UK, of 1303 pregnant women aged $18-45$ years.

Questionnaires assessed alcohol consumption before pregnancy and for the three trimesters separately. Categories of alcohol consumption were divided into $\leq 2$ units/week and $>2$ units/week with a nondrinking category as referent. This was related to size at birth and preterm delivery, adjusting for confounders including salivary cotinine as a biomarker of smoking status.

Results Nearly two-thirds of women before pregnancy and over half in the first trimester reported alcohol intakes above the Department of Health (UK) guidelines of $\leq 2$ units/week. Associations with birth outcomes were strongest for intakes $>2$ units/week before pregnancy and in trimesters 1 and 2 compared to non-drinkers. Even women adhering to the guidelines in the first trimester were at significantly higher risk of having babies with lower birth weight, lower birth centile and preterm birth compared to non-drinkers, after adjusting for confounders $(p<0.05)$.

Conclusions We found the first trimester to be the period most sensitive to the effect of alcohol on the developing fetus. Women adhering to guidelines in this period were still at increased risk of adverse birth outcomes. Our findings suggest that women should be advised to abstain from alcohol when planning to conceive and throughout pregnancy.

\section{INTRODUCTION}

Alcohol was confirmed as a teratogen in the late 1970s after observations made in France and the USA in infants born to alcoholic mothers. ${ }^{12}$ Evidence regarding the damaging effects of heavy drinking in pregnancy is now well established. However, there is a lack of consensus regarding the impact of low intakes on adverse birth outcomes such as preterm birth and small for gestational age (SGA), with studies reporting a wide range and even a protective effect of low intakes in reviews of the evidence. ${ }^{3-10}$ This is reflected in the different country-level policies regarding alcohol consumption during pregnancy and highlighted in a recent review by O'Leary et al on alcohol policies in English-speaking countries. ${ }^{11}$ Some, such as the USA, recommend abstinence. ${ }^{12}$ Others advise abstinence but state that small amounts of alcohol are unlikely to cause harm. ${ }^{13}$ In the UK, the Department of Health (DH) recommends that pregnant women and women trying to conceive should avoid alcohol altogether and never drink more than 1-2 units once or twice a week. ${ }^{14}$ The National Institute for Health and Care Excellence (NICE) additionally emphasises the advice to avoid drinking alcohol in the first 3 months of pregnancy as this may be associated with an increased risk of miscarriage. ${ }^{15}$

According to the UK Health Survey 2011, 52\% of women of childbearing age who drink exceed the daily limit of 2-3 units per day and 25\% drink more than twice the recommendations. ${ }^{16}$ Results from the most recent UK Infant Feeding Survey (IFS) which included data from over 15000 women, showed that $40 \%$ drank alcohol during pregnancy but only $3 \%$ drank more than 2 units per week. ${ }^{17}$

Data suggest that over $40 \%$ of pregnancies in the UK are unplanned. ${ }^{18}{ }^{19}$ With such high rates of unplanned pregnancies and excess drinking, early pregnancy is likely to be the period of highest intake for women who are unaware of their pregnancy, and this could put them and their unborn baby at risk.

Alcohol crosses the placenta and results in nearly equal concentrations in the mother and fetus. The mechanisms whereby alcohol affects fetal growth and development are complex as these are staged processes, and the sensitivity of the fetus to alcohol will likely depend on the timing of the exposure. ${ }^{6}$ Few studies have taken into account the effect of timing of alcohol exposure on birth outcomes. Examination of alcohol consumption before pregnancy and for all trimesters separately showed conflicting results as to which period is most sensitive; some studies found an association between alcohol intake and SGA and preterm birth at all levels of exposure, while others suggested no association even at high levels of intake. ${ }^{20-23}$

The aims of this paper were to investigate the relationship between maternal alcohol intake during pregnancy with both birth weight and gestational age, and to assess whether these relationships differed by timing of exposure during pregnancy. We also aimed to investigate the effect of maternal drinking prior to pregnancy on birth outcomes. This was accomplished using data from a prospective cohort. 


\section{METHODS}

\section{Study design, participants and data collection}

The Caffeine and Reproductive Health (CARE) Study was a prospective study into maternal diet and birth outcomes. Between 2003 and 2006, low risk pregnant women aged 18-45 were prospectively recruited from the Leeds Teaching Hospitals Trust. The study methodology has been described in detail elsewhere. ${ }^{24}$ Women were excluded if they had any concurrent medical disorders, psychiatric illness, HIV infection or hepatitis B infection. A total of 5959 women were considered, of whom 4571 met the eligibility criteria. Eligible women were sent detailed information about the study and 1374 consented to participate. The study was approved by the Leeds West Local Research Ethics Committee (ref 03/054).

\section{Assessment of alcohol consumption and diet}

Alcohol intake was assessed throughout pregnancy using a food frequency approach adapted from the UK Women's Cohort Study administered at enrolment (12-18 weeks gestation), week 28 and postpartum (weeks 46-50). ${ }^{25}$ Consumption was assessed for 4 weeks prior to pregnancy through to week 12 of gestation, weeks 13-28 and weeks 29-40. Participants were asked how often (never, less than once/month, 1-3 times/month, once/ week, 2-4 times/week, 5-6 times/week, once/day, 2-3 times/day, 4-5 times/day and $>6$ times/day) they consumed different types of alcohol (wine, beer/lager/stout, cider, port/sherry/liqueurs, vodka kick and spirits). Frequency of alcohol consumption derived from the questionnaires was converted to times per week, which was then multiplied by the units of alcohol in each of the alcoholic beverages listed on the questionnaire to obtain weekly consumption in units for each of the time periods. For wine, the units of alcohol per portion for each type of alcoholic beverage was 2.3 for beer, 2.0 for cider, 1.0 for port and spirits, and 1.5 for vodka kick. This is in accordance with the conversion factors used since 2006 in the Health Survey of England, one unit of alcohol equating to $10 \mathrm{~mL}$ by volume or $8 \mathrm{~g}$ by weight. ${ }^{16}$

Dietary intake was reported on a $24 \mathrm{~h}$ dietary recall questionnaire administered by a research midwife at 16 weeks gestation. Daily total energy intake was derived from the reported food intake.

\section{Assessment of outcomes}

Information on birth outcomes was obtained from hospital maternity records. The primary outcome assessed was size at birth, recorded as grams, as well as customised birth centiles which took into account maternal height, weight, ethnicity, parity, neonatal birth weight and sex. ${ }^{26}$ The relationship with preterm delivery (<37 weeks gestation) and SGA $(<10$ th centile) was also investigated.

\section{Assessment of participant characteristics}

Salivary cotinine levels were measured at enrolment using ELISA (Cozart Bioscience, Abingdon, UK). Participants were classified on the basis of cotinine concentrations as active smokers $(>5 \mathrm{ng} / \mathrm{mL})$, passive smokers $(1-5 \mathrm{ng} / \mathrm{mL})$ or nonsmokers $(<1 \mathrm{ng} / \mathrm{mL}){ }^{27}$

Maternal characteristics such as pre-pregnancy weight, height, age, ethnicity (European, Asian, Afro-Caribbean, African, Mixed/Other origin), parity $(0,1,2,3,4+)$, caffeine intake and maternal education (none, O-level, A-level, degree) were obtained via a self-reported questionnaire administered at enrolment.
Statistical power calculation

Comparison of birth weight between non-drinkers and drinkers and the SD of birth weight identified in the study $(\mathrm{SD}=576 \mathrm{~g})$ demonstrated that the study had $85 \%$ power to detect a difference of just over $-100 \mathrm{~g}$ in birth weight for a two-sided t test at $\mathrm{p}<0.05$ in trimester 1 .

\section{Statistical methods}

Analysis was undertaken using the continuous weekly alcohol variable divided into categories of intake based on the $\mathrm{DH}$ (2008) guidelines of no more than 2 units/week with the inclusion of a non-drinking category which was used as the reference group ( 0 units/week, $\leq 2$ units/week and $>2$ units/week).

Univariable analyses were performed using one-way ANOVA for normally distributed outcomes and the Kruskal-Wallis test otherwise. The $\chi^{2}$ test was used for categorical outcomes.

Data were further analysed using multivariable linear regression for continuous outcomes and multivariable logistic regression for binary outcomes. Maternal pre-pregnancy weight, height, parity, ethnicity, gestation and baby's sex were taken into account when calculating the customised birth centile and were adjusted for in the model for birth weight and preterm delivery. Further statistical adjustment was made, based on a priori knowledge from the literature, for maternal age, salivary cotinine levels, caffeine intake and maternal education (as a proxy for socioeconomic status). Because of the possible correlation between alcohol consumption and energy intake, energy intake obtained from the $24 \mathrm{~h}$ recalls was included in the model, as it was important to distinguish between the separate effects of alcohol and energy intake on birth outcomes. ${ }^{28}$ Extreme values for energy intake (1\% highest and 1\% lowest) were excluded based on the method proposed by Meltzer et al. ${ }^{29}$ The robustness of the results to excluding women with conditions known to predispose to adverse birth outcomes, including a previous low birthweight (LBW) baby, gestational diabetes and gestational hypertension, as well as women of childbearing age who were "risky drinkers" (defined by the Centers for Disease Control and Prevention as those consuming more than 7 US drinks per week, corresponding to $10 \mathrm{UK}$ units $^{30}$ ) was also assessed.

All analyses were carried out using Stata V.12 (Stata, College Station, Texas, USA).

\section{RESULTS}

A total of 1303 women were recruited, and of these 1294 had data available on birth outcomes. Five women had terminations and were therefore excluded from this analysis. An additional 25 women were excluded due to extreme energy intakes (the $1 \%$ highest and $1 \%$ lowest intakes).

\section{Alcohol intake}

Of the remaining 1264 women, 1153 (91\%), 1135 (90\%), 793 $(66 \%)$ and $377(30 \%)$ completed the questions on alcohol intake before pregnancy, and during the 1st trimester, 2nd trimester and 3rd trimester, respectively (table 1). Alcohol intakes before pregnancy and in the first trimester were significantly higher $(\mathrm{p}<0.0001)$ than in the 2 nd and 3rd trimesters $(11.2$, 4.0, 1.8 and 1.9 units/week, respectively). The prevalence of women consuming more than 2 units per week was highest before pregnancy $(74 \%)$ and in the 1 st trimester $(53 \%)$, with mean intakes for women reaching 15.1 units (95\% CI 14.1 to $16.1)$ and 7.2 units (95\% CI 6.6 to 7.9 ) per week, respectively. The prevalence of "risky drinkers" was relatively low at $11 \%$, $2 \%$ and $3 \%$ for trimesters 1,2 and 3 , respectively, but much 
Table 1 Self-reported alcohol intake among pregnant women in the CARE study

\begin{tabular}{|c|c|c|c|}
\hline Characteristic & n (\% total sample) & Mean & $95 \% \mathrm{Cl}$ \\
\hline \multicolumn{4}{|l|}{ Alcohol intake (units/week)* } \\
\hline 4 Weeks before pregnancy & $1153(100.0)$ & 11.2 & 10.4 to 12.1 \\
\hline First trimester & $1135(98.4)$ & 4.0 & 3.6 to 4.4 \\
\hline Second trimester & $793(68.8)$ & 1.8 & 1.6 to 2.0 \\
\hline Third trimester & $377(32.7)$ & 1.9 & 1.5 to 2.3 \\
\hline \multicolumn{4}{|c|}{ Categories of intake 4 weeks before pregnancy $\dagger$} \\
\hline Non-drinkers & $157(13.6)$ & 0 & 0 \\
\hline$\leq 2$ Units/week & $148(12.8)$ & 0.9 & 0.9 to 1.1 \\
\hline >2 Units/week & $848(73.6)$ & 15.1 & 14.1 to 16.1 \\
\hline \multicolumn{4}{|l|}{ Categories of intake trimester 1} \\
\hline Non-drinkers & $243(21.4)$ & 0 & 0 \\
\hline$\leq 2$ Units/week & $292(25.7)$ & 0.8 & 0.7 to 0.8 \\
\hline$>2$ Units/week & $600(52.9)$ & 7.2 & 6.6 to 7.9 \\
\hline \multicolumn{4}{|l|}{ Categories of intake trimester 2} \\
\hline Non-drinkers & $291(36.7)$ & 0 & 0 \\
\hline$\leq 2$ Units/week & $278(35.1)$ & 0.8 & 0.8 to 0.9 \\
\hline >2 Units/week & $224(28.3)$ & 5.4 & 4.8 to 5.9 \\
\hline \multicolumn{4}{|l|}{ Categories of intake trimester 3} \\
\hline Non-drinkers & $193(51.2)$ & 0 & 0 \\
\hline$\leq 2$ Units/week & $80(21.2)$ & 0.9 & 0.8 to 1.0 \\
\hline >2 Units/week & $104(27.6)$ & 6.3 & 5.2 to 7.3 \\
\hline
\end{tabular}

higher before pregnancy, with $38 \%$ of women consuming more than 10 units/week.

\section{Characteristics of women according to categories of alcohol intake}

Table 2 shows the characteristics of participants according to alcohol consumption. Women with alcohol intakes above 2 units per week were more likely to be older, have a university degree and be of European origin and less likely to live in an area within the most deprived Index of Multiple Deprivation (IMD) quartile. These characteristics were consistent across all trimesters. However, in trimester 1, women in the high consumption category were also more likely to have a higher total energy intake compared to the other two categories and to have no children. Apart from differences in energy intake, the same differences between the women seen in trimester 1 were also true for the 4 weeks before pregnancy (results not shown).

\section{Birth outcomes}

Of the 1264 women with information on birth outcomes, 166 (13.1\%) babies weighed less than the 10th centile. Fifty-seven $(4.4 \%)$ were $\mathrm{LBW}(<2500 \mathrm{~g})$ and $54(4.3 \%)$ were delivered preterm ( $<37$ weeks gestation).

\section{Relationship between alcohol intake and size at birth}

There was a strong association between alcohol intake before pregnancy and birth weight and birth centile after adjustments for maternal pre-pregnancy weight, height, parity, ethnicity, gestation, baby's sex, maternal age, salivary cotinine levels, caffeine intake and maternal education (table 3). Women who adhered to the guidelines were not at increased risk, but compared to non-drinkers, alcohol intakes of $>2$ units/week were associated with a -7.7 (95\% CI -12.8 to -2.6$)$ decrease in customised birth centile (adjusted $p_{\text {trend }}=0.009$ ).

For consumption during pregnancy, after adjustments, alcohol consumption was associated with an approximately $100 \mathrm{~g}$ reduction in birth weight for women consuming $>2$ units/week in trimester $1\left(\mathrm{p}_{\text {trend }}=0.007\right)$. Compared to non-drinkers, alcohol intakes of $<2$ units/week and $>2$ units/week in trimester 1 were associated with an adjusted $-5.8(95 \% \mathrm{CI}-10.8$ to -0.7$)$ and a $-8.2(95 \%$ CI -12.6 to -3.7$)$ decrease in customised birth centile, respectively $\left(\mathrm{p}_{\text {trend }}=0.002\right)$. The adjusted ORs for SGA were 1.7 (95\% CI 0.9 to 3.1) for intakes <2 units/week and 2.0 (95\% CI 1.2 to 3.4 ) for intakes $>2$ units/week in trimester 1 $\left(\mathrm{p}_{\text {trend }}=0.03\right)$ compared to non-drinkers. These associations were attenuated in trimester 2 and 3.

\section{Relationship between alcohol intake and preterm birth}

Compared to non-drinkers in trimester 1 , the adjusted OR for having a preterm baby were $4.6(95 \%$ CI 1.4 to 14.7$)$ for intakes $<2$ units/week and 3.5 (1.1 to 11.2) for intakes >2 units/week (table 4). For the 4 weeks before pregnancy (table 3 ) and in trimesters 2 and 3 (table 4), the association was non-significant.

\section{Sensitivity analysis}

Including total energy intake in the model further strengthened the association between maternal alcohol intakes during pregnancy and birth outcomes; however, it did not influence results for intakes before pregnancy.

Excluding women with high risk pregnancies $(n=182)$ and "risky drinkers" did not alter the results, although the CIs became wider due to the reduction in numbers (results not shown).

\section{DISCUSSION}

This is one of very few prospective studies ${ }^{20-23} 3132$ and the first in a British cohort which has looked at alcohol exposures before pregnancy and in each of the trimesters separately, and their association with adverse birth outcomes. Maternal alcohol intake during the first trimester was found to have the strongest association with fetal growth and gestational age. Women who adhered to guidelines in this period were still at increased risk of adverse birth outcomes even after adjustment for known risk factors. Maternal alcohol intakes which exceeded the recommendations in the period leading up to pregnancy were also found to be associated with fetal growth, suggesting that the peri-conceptual period could be particularly sensitive to the effects of alcohol on the fetus. Our results highlight the need for endorsing the abstinence-only message, and further illuminate how timing of exposure is important in the association of alcohol with birth outcomes, with the first trimester being the most vulnerable period.

\section{Alcohol intake and maternal characteristics}

As expected, intakes of alcohol were highest in the 4 weeks before pregnancy, with decreasing levels observed as pregnancy progressed. The proportion of women drinking during pregnancy $(79 \%, 63 \%$ and $49 \%$ for trimesters 1,2 and 3, respectively) was considerable higher than reported from the IFS. ${ }^{7}$ IFS data, however, were collected postpartum and are therefore subject to under-reporting. The characteristics of drinking mothers in our study are consistent with those observed in the IFS where mothers aged 35 or over, from managerial and professional occupations and from a white ethnic background were more likely to drink during pregnancy. ${ }^{17}$ Despite the high 
Table 2 Characteristics of mothers by alcohol intake during pregnancy reported in three questionnaires*

\begin{tabular}{|c|c|c|c|c|c|c|c|c|c|c|c|c|}
\hline & \multicolumn{4}{|l|}{ First trimester $(n=1135)$} & \multicolumn{4}{|c|}{ Second trimester $(\mathrm{n}=808)$} & \multicolumn{4}{|l|}{ Third trimester $(\mathrm{n}=384)$} \\
\hline & $\begin{array}{l}\text { Non-drinkers } \\
(\mathrm{n}=243)\end{array}$ & $\begin{array}{l}\leq 2 \text { Units/week } \\
(n=298)\end{array}$ & $\begin{array}{l}>2 \text { Units/week } \\
(\mathrm{n}=594)\end{array}$ & $\mathrm{p}$ Valuet & $\begin{array}{l}\text { Non-drinkers } \\
(\mathrm{n}=300)\end{array}$ & $\begin{array}{l}\leq 2 \text { Units/week } \\
(n=282)\end{array}$ & $\begin{array}{l}>2 \text { Units/week } \\
(n=226)\end{array}$ & $\mathrm{p}$ Valuet & $\begin{array}{l}\text { Non-drinkers } \\
(\mathrm{n}=197)\end{array}$ & $\begin{array}{l}\leq 2 \text { Units/week } \\
(n=82)\end{array}$ & $\begin{array}{l}>2 \text { Units/week } \\
(\mathrm{n}=105)\end{array}$ & $\mathrm{p}$ Valuet \\
\hline Age (years), mean $(95 \% \mathrm{Cl})$ & $29.4(28.7$ to 30.1$)$ & $29.5(28.9$ to 30.1$)$ & 30.5 (30.1 to 30.9$)$ & 0.002 & $28.9(28.3$ to 29.5$)$ & 30.7 (30.2 to 31.3$)$ & 31.8 (31.2 to 32.3$)$ & $<0.0001$ & 28.5 (27.8 to 29.3$)$ & $30.8(29.9$ to 31.7$)$ & 30.7 (29.8 to 31.6$)$ & 0.0005 \\
\hline $\begin{array}{l}\text { Pre-pregnancy BMI }\left(\mathrm{kg} / \mathrm{m}^{2}\right) \text {, } \\
\text { mean }(95 \% \mathrm{Cl})\end{array}$ & 25.0 (24.4 to 25.7 ) & 24.7 (24.1 to 25.3$)$ & 24.5 (24.1 to 24.9$)$ & 0.5 & 25.1 (24.4 to 25.8$)$ & 24.5 (23.9 to 25.0$)$ & 23.9 (23.3 to 24.4$)$ & 0.1 & 25.5 (24.6 to 26.4 ) & 24.0 (23.0 to 25.0$)$ & 23.9 (23.2 to 24.8 ) & 0.1 \\
\hline $\begin{array}{l}\text { Total energy intake (kcal), } \\
\text { mean }(95 \% \mathrm{Cl})\end{array}$ & 2060 (1778 to 2136) & 2079 (2012 to 2146) & 2162 (2111 to 2213) & 0.04 & 2075 (2007 to 2144) & 2169 (2099 to 2239) & 2181 (2097 to 2264) & 0.08 & 2080 (1990 to 2170$)$ & 2142 (2013 to 2277 ) & 2156 (2036 to 2276) & 0.5 \\
\hline $\begin{array}{l}\text { Caffeine intake (mg/day), } \\
\text { mean }(95 \% \mathrm{Cl})\end{array}$ & 176.1 (152.7 to 199.4$)$ & $174.2(153.3$ to 195.1$)$ & 202.0 (186.3 to 217.8 ) & 0.06 & 163.0 (139.2 to 186.8$)$ & 158.0 (138.8 to 177.3$)$ & 175.7 (155.8 to 195.6$)$ & 0.009 & 206.1 (171.4 to 240.9) & 223.3 (170.8 to 275.7$)$ & 189.4 (158.9 to 219.8$)$ & 0.4 \\
\hline Smoker at 12 weeks, \% (n) & $17.4(40)$ & $18.3(53)$ & $14.9(85)$ & 0.6 & $14.6(41)$ & $12.4(33)$ & $9.6(21)$ & 0.2 & $22.7(42)$ & $18.8(15)$ & $11.9(12)$ & 0.2 \\
\hline IMD most deprived quartile, $\%$ (n) & $37.5(87)$ & $32.7(93)$ & $23.3(134)$ & 0.0001 & $32.7(91)$ & $21.4(58)$ & $16.3(35)$ & 0.0001 & $34.1(63)$ & $25.6(20)$ & $15.5(15)$ & 0.003 \\
\hline University degree, \% (n) & $34.6(84)$ & $39.3(117)$ & $43.6(259)$ & 0.05 & $35.1(102)$ & $49.1(137)$ & $51.6(115)$ & 0.0002 & $28.5(55)$ & $40.0(32)$ & $50.9(53)$ & 0.0001 \\
\hline European origin, \% (n) & $85.5(206)$ & $94.9(283)$ & $98.2(582)$ & 0.0001 & $92.0(266)$ & $96.8(270)$ & $99.1(220)$ & 0.001 & $94.8(181)$ & $96.3(77)$ & $99.0(102)$ & 0.4 \\
\hline Primigravida, \% (n) & $36.6(89)$ & 43.7 (119) & $53.8(317)$ & 0.0001 & $52.4(152)$ & $49.8(138)$ & $47.9(107)$ & 0.6 & $52.1(100)$ & $47.5(38)$ & $56.7(59)$ & 0.5 \\
\hline Preterm labour, \% (n) & $2.1(5)$ & $6.0(18)$ & $4.7(28)$ & 0.08 & $5.2(15)$ & $3.9(11)$ & $4.5(10)$ & 0.8 & $7.3(14)$ & 7.5 (6) & $5.8(6)$ & 0.9 \\
\hline Pre-eclampsia, \% (n) & $5.8(14)$ & $5.1(15)$ & $4.0(28)$ & 0.8 & $5.9(17)$ & $7.3(20)$ & $2.3(5)$ & 0.05 & 7.5 (14) & $5.1(4)$ & $2.9(3)$ & 0.3 \\
\hline Past history of miscarriage, \% (n) & $26.3(63)$ & $22.4(66)$ & $22.3(133)$ & 0.5 & $27.2(78)$ & 23.1 (64) & $22.1(49)$ & 0.3 & $23.2(44)$ & $17.5(14)$ & $23.5(24)$ & 0.5 \\
\hline
\end{tabular}

${ }^{*}$ Division of alcohol intake is based on the Department of Health (2008) weekly recommendations of no more than 2 units/week. ${ }^{4}$

tp Value using one-way ANOVA for normally distributed and Kruskal-Wallis test for non-normally distributed continuous variables, and the $\chi^{2}$ test and Fisher's exact test for categorical variables. Significant difference at $p<0.05$.

BMI, body mass index; IMD, Index of Multiple Deprivation.
B. 
Table 3 The relationship between maternal alcohol intake 4 weeks before pregnancy and size at birth and preterm delivery ( $\mathrm{n=1152)}$

\begin{tabular}{|c|c|c|c|c|}
\hline & Unadjusted change $(95 \% \mathrm{Cl})$ & p Value* & Adjusted changet $(95 \% \mathrm{Cl})$ & p Value* \\
\hline \multicolumn{5}{|l|}{ Birth weight $(\mathrm{g})$} \\
\hline Non-drinkers & 0.0 & 0.9 & 0.0 & 0.03 \\
\hline$\leq 2$ Units/week & $-14.6(-147.4$ to 118.1$)$ & & $-70.2(-167.4$ to 26.9$)$ & \\
\hline$>2$ Units/week & $-23.2(-123.6$ to 77.1$)$ & & $-105.7(-183.5$ to -27.9$)$ & \\
\hline \multicolumn{5}{|c|}{ Customised birth centile $\ddagger$} \\
\hline Non-drinkers & 0.0 & 0.1 & 0.0 & 0.009 \\
\hline$\leq 2$ Units/week & $-2.8(-9.4$ to 3.9$)$ & & $-4.2(-10.9$ to 2.4$)$ & \\
\hline \multirow[t]{2}{*}{ >2 Units/week } & $-4.9(-9.9$ to 0.1$)$ & & $-7.7(-12.8$ to -2.6$)$ & \\
\hline & Unadjusted OR (95\% Cl) & p Value* & Adjusted ORt $(95 \% \mathrm{Cl})$ & $p$ Value* \\
\hline \multicolumn{5}{|c|}{ SGA (<10th centile) $\ddagger$} \\
\hline Non-drinkers & 1.0 & 0.5 & 1.0 & 0.2 \\
\hline$\leq 2$ Units/week & $1.4(0.7$ to 2.7$)$ & & 1.7 (0.8 to 3.5$)$ & \\
\hline >2 Units/week & $1.4(0.8$ to 2.3$)$ & & $1.8(0.9$ to 3.2$)$ & \\
\hline \multicolumn{5}{|c|}{ Low birth weight $(\leq 2500 \mathrm{~g})$} \\
\hline Non-drinkers & 1.0 & 0.5 & 1.0 & 0.4 \\
\hline$\leq 2$ Units/week & $0.6(0.2$ to 1.7$)$ & & 0.4 (0.1 to 2.7$)$ & \\
\hline$>2$ Units/week & 0.9 (0.4 to 2.2$)$ & & $1.1(0.2$ to 6.1$)$ & \\
\hline \multicolumn{5}{|c|}{ Preterm birth ( $<37$ weeks gestation) } \\
\hline Non-drinkers & 1.0 & 0.9 & 1.0 & 0.5 \\
\hline$\leq 2$ Units/week & $1.4(0.7$ to 2.7$)$ & & $1.7(0.6$ to 6.4$)$ & \\
\hline$>2$ Units/week & $1.4(0.8$ to 2.3$)$ & & $2.0(0.7$ to 6.2$)$ & \\
\hline
\end{tabular}

*p For trend for categories of alcohol intake.

tAdjusted for maternal pre-pregnancy weight, height, age, parity, ethnicity, salivary cotinine levels, caffeine intake, education, energy intake, gestation and baby's sex in a multivariable linear regression for continuous outcomes and a multivariable logistic regression for categorical outcomes.

¥Takes into account maternal pre-pregnancy weight, height, parity, ethnicity, gestation and baby's sex.

SGA, small for gestational age.

prevalence of drinking in our cohort, very few women were considered risky drinkers. The low level of intake could in part be explained by under-reporting, a common phenomenon in alcohol assessment. ${ }^{6}$ Reported alcohol consumption in surveys only accounts for approximately $60 \%$ of total alcohol sales and a recent study found evidence that excess alcohol drinking in the UK may be higher than previously thought. ${ }^{33}$ The actual level of intake may therefore be higher than reported, and associations with adverse birth outcomes could be with higher levels of intake.

\section{Timing of exposure and birth outcomes}

We found consistently adverse associations between intakes of alcohol above 2 units/week prior to pregnancy and in the 1 st and 2 nd trimester and birth weight. In a prospective US cohort study, a reduction in birth weight was found in women drinking more than 2 units/week across all trimesters. ${ }^{32}$ However, the numbers were small once divided into categories of intake, and the reduction was not significant with very wide CIs.

We found a significant twofold increase in the odds of babies being born SGA to mothers drinking more than 2 units/week compared to non-drinkers in trimester 1 . O'Leary et al reported significantly increased odds of infants being born SGA to women drinking up to $60 \mathrm{~g}$ alcohol/week (7.5 UK units) 3 months prior to pregnancy, an association, however, which was not observed at higher levels of alcohol or for consumption during pregnancy. ${ }^{22}$ Two studies ${ }^{21} 31$ found an elevated risk of babies being born SGA to drinking mothers, but the threshold of intake was much higher than observed in our study. Chiaffarino et al reported significantly increased odds of a baby being born SGA at daily intakes above 3 units compared to abstainers across all trimesters and before pregnancy, but the association was strongest for intakes in trimester $1 .{ }^{21}$ Feldman et al found a dose-response relationship with a $16 \%$ increase for reduced birth weight for every one drink increase per day in the second half of trimester 1 and for all of trimester 2. ${ }^{31}$

We found an elevated risk of preterm birth in drinkers compared to abstainers in trimester 1 only. This is comparable to findings reported by other studies. ${ }^{22}{ }^{23}$ However, the threshold of increased risk was much higher than that observed in our study. In contrast, a recent study found a decreased risk in women consuming up to three drinks per week compared to abstainers in the third trimester. ${ }^{20}$

The differences between our findings and those of other studies are partly due to heterogeneity between studies; in particular, we looked at very low intakes of alcohol and their associations with birth outcomes. Where studies have found similar associations, this has been in relation to a much higher intake.

We have included studies which accounted for timing of exposure, but the methodology of studies differed greatly. None used the same method of alcohol assessment. In addition, the period before pregnancy was not specified in some studies, ${ }^{21} 23$ and for others, numbers were very small in the higher categories of intake, limiting their power to detect a true association. ${ }^{21} 2232$ Moreover, choice of confounders was also highly inconsistent across studies; in our study, for example, we adjusted for cotinine levels and energy intake, both of which have not been adjusted for in previous research. Additionally, inconsistency in findings between countries may be a reflection of differences in drinking patterns. Finally, differences could also be due to polymorphisms linked to the metabolism of alcohol, ${ }^{34}$ which may vary between populations. This heterogeneity makes it hard to compare results. 
Table 4 The relationship between maternal alcohol intake during pregnancy and size at birth and preterm delivery

\begin{tabular}{|c|c|c|c|c|c|c|c|c|c|c|c|c|}
\hline & \multicolumn{3}{|l|}{ Trimester $1(n=1135)$} & \multirow[b]{2}{*}{$p$ Value* } & \multicolumn{3}{|l|}{ Trimester $2(\mathrm{n}=793)$} & \multirow[b]{2}{*}{ p Value* } & \multicolumn{3}{|l|}{ Trimester $3(n=377)$} & \multirow[b]{2}{*}{ p Value* } \\
\hline & $\begin{array}{l}\text { Unadjusted change } \\
(95 \% \mathrm{Cl})\end{array}$ & $p$ Value* & $\begin{array}{l}\text { Adjusted changet } \\
(95 \% \mathrm{Cl})\end{array}$ & & $\begin{array}{l}\text { Unadjusted change } \\
(95 \% \mathrm{Cl})\end{array}$ & p Value* & $\begin{array}{l}\text { Adjusted changet } \\
(95 \% \mathrm{Cl})\end{array}$ & & $\begin{array}{l}\text { Unadjusted change } \\
(95 \% \mathrm{Cl})\end{array}$ & p Value* & $\begin{array}{l}\text { Adjusted change } \\
(95 \% \mathrm{Cl})\end{array}$ & \\
\hline \multicolumn{13}{|l|}{ Birth weight (g) } \\
\hline Non-drinkers & 0.0 & 0.02 & 0.0 & 0.007 & 0.0 & 0.5 & 0.0 & 0.04 & 0.0 & 0.6 & 0.0 & 0.6 \\
\hline$\leq 2$ Units/week & $-124.8(-225.4$ to -24.3$)$ & & $-98.5(-170.9$ to -26.1$)$ & & $51.3(-42.5$ to 145.0$)$ & & $-37.6(-108.1$ to 32.8$)$ & & $4.2(-162.4$ to 170.7$)$ & & $-34.5(-153.1$ to 84.1$)$ & \\
\hline >2 Units/week & $-105.9(-193.9$ to -17.9$)$ & & $-100.4(-165.8$ to -34.9$)$ & & $12.9(-56.5$ to 112.2$)$ & & $-99.6(-175.8$ to -22.3$)$ & & 73.7 (-78.6 to 226.1$)$ & & $-50.4(-161.2$ to -60.3$)$ & \\
\hline \multicolumn{13}{|c|}{ Customised birth centile‡ } \\
\hline Non-drinkers & 0.0 & 0.01 & 0.0 & 0.002 & 0.0 & 0.5 & 0.0 & 0.06 & 0.0 & 0.8 & 0.0 & 0.7 \\
\hline$\leq 2$ Units/week & $-4.1(-9.1$ to -0.9$)$ & & $-5.8(-10.8$ to -0.7$)$ & & $-1.4(-6.3$ to 3.5$)$ & & $-3.6(-8.6$ to 1.4$)$ & & $-1.4(-9.4$ to 6.6$)$ & & $-3.1(-11.1$ to 4.9$)$ & \\
\hline \multirow[t]{2}{*}{$>2$ Units/week } & $-6.7(-11.1$ to -2.3$)$ & & $-8.2(-12.6$ to -3.7$)$ & & $-2.9(-8.2$ to 2.2$)$ & & $-6.4(-11.8$ to -1.1$)$ & & $1.2(-6.1$ to 8.5$)$ & & $-1.8(-9.3$ to 5.7$)$ & \\
\hline & $\begin{array}{l}\text { Unadjusted OR } \\
(95 \% \mathrm{CI})\end{array}$ & $p$ Value* ${ }^{*}$ & $\begin{array}{l}\text { Adjusted ORt } \\
(95 \% \mathrm{Cl})\end{array}$ & $p$ Value $^{*}$ & $\begin{array}{l}\text { Unadjusted } \\
\text { OR }(95 \% \mathrm{CI})\end{array}$ & p Value* & $\begin{array}{l}\text { Adjusted ORt } \\
(95 \% \mathrm{Cl})\end{array}$ & $p$ Value $^{*}$ & $\begin{array}{l}\text { Unadjusted OR } \\
(95 \% \mathrm{Cl})\end{array}$ & $p$ Value* & $\begin{array}{l}\text { Adjusted ORt } \\
(95 \% \mathrm{Cl})\end{array}$ & p Value* \\
\hline \multicolumn{13}{|c|}{ SGA (<10th centile)‡ } \\
\hline Non-drinkers & 1.0 & 0.08 & 1.0 & 0.03 & 1.0 & 0.2 & 1.0 & 0.2 & 1.0 & 0.9 & 1.0 & 0.7 \\
\hline$\leq 2$ Units/week & $1.4(0.8$ to 2.5$)$ & & 1.7 (0.9 to 3.1$)$ & & $0.7(0.4$ to 1.0$)$ & & $0.8(0.5$ to 1.3$)$ & & $0.9(0.5$ to 1.5$)$ & & $0.9(0.5$ to 1.6$)$ & \\
\hline$>2$ Units/week & $1.7(1.1$ to 2.8$)$ & & 2.0 (1.2 to 3.4$)$ & & $0.9(0.6$ to 1.5$)$ & & $1.2(0.8$ to 2.1$)$ & & $0.9(0.6$ to 1.6$)$ & & $1.2(0.7$ to 2.1$)$ & \\
\hline \multicolumn{13}{|c|}{ Low birth weight $(\leq 2500 \mathrm{~g})$} \\
\hline Non-drinkers & 1.0 & 0.20 & 1.0 & 0.8 & 1.0 & 0.4 & 1.0 & 0.7 & 1.0 & 0.7 & 1.0 & 0.7 \\
\hline$\leq 2$ Units/week & $0.4(0.2$ to 1.0$)$ & & $1.6(0.3$ to 7.4$)$ & & $1.4(0.7$ to 2.8$)$ & & $0.7(0.2$ to 2.9$)$ & & $1.1(0.5$ to 2.4$)$ & & $0.3(0.02$ to 4.1$)$ & \\
\hline$>2$ Units/week & $0.6(0.2$ to 1.3$)$ & & $1.6(0.4$ to 6.4$)$ & & $1.6(0.7$ to 3.4$)$ & & $1.5(0.3$ to 8.4$)$ & & $1.4(0.6$ to 3.2$)$ & & 1.8 (0.1 to 29.8$)$ & \\
\hline \multicolumn{13}{|c|}{ Preterm birth ( $<37$ weeks gestation) } \\
\hline Non-drinkers & 1.0 & 0.08 & 1.0 & 0.04 & 1.0 & 0.8 & 1.0 & 0.8 & 1.0 & 0.9 & 1.0 & 0.9 \\
\hline$\leq 2$ Units/week & 3.1 (1.1 to 8.6$)$ & & 4.6 (1.4 to 14.7$)$ & & $0.8(0.3$ to 1.7$)$ & & $0.8(0.3$ to 1.8$)$ & & $1.0(0.4$ to 2.8$)$ & & $1.0(0.3$ to 3.2$)$ & \\
\hline$>2$ Units/week & $2.3(0.9$ to 6.1$)$ & & $3.5(1.1$ to 11.2$)$ & & $0.9(0.4$ to 1.9$)$ & & $0.9(0.43$ to 2.1$)$ & & $0.8(0.3$ to 2.1$)$ & & $1.0(0.3$ to 2.9$)$ & \\
\hline
\end{tabular}

${ }^{*} p$ For trend for categories of alcohol intake in a multivariable linear regression for continuous outcomes and a multivariable logistic regression for categorical outcomes.

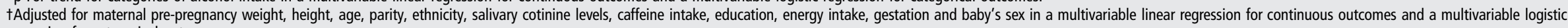

regression for categorical outcomes.
¥Takes into account maternal pre-pregnancy weight, height, parity, ethnicity, gestation and baby's sex.

SGA, small for gestational age. 


\section{Methodological considerations}

Alcohol intake was averaged to weekly consumption and then divided into categories. This was done so as to better reflect the current UK guidelines on alcohol consumption for pregnant women and women trying to conceive, and to make the results more applicable in a public health context. Although this prevented us looking at associations with patterns of intake, such as binge drinking, the number of risky drinkers was very low and we would have had little power to detect a true association. Furthermore, the categories included a non-drinking referent and compared low levels of drinking, which is appropriate in a moderate to low drinking population. Units and their alcohol content were clearly defined in our study. Serving sizes and the alcohol content of drinks, however, may differ between mothers. The calculation of alcoholic content of beverages was in line with the alcoholic profile of beers, wine and spirits at the time of data collection, a detail often omitted in other studies. ${ }^{31}$ This is important to prevent exposure misclassification which may obscure any relationship with birth outcomes as the alcohol profile of beverages is known to change over time. ${ }^{16}$

A major strength of this study is the objective measurement of smoking, one of the biggest confounders in the relationship between alcohol and adverse birth outcomes, by using cotinine as a biomarker.

Considering timing of exposure is important so that variation in alcohol consumption throughout pregnancy can be identified. Moreover, the timing of exposure will affect birth outcomes differently as fetal development is a staged process and, for this reason, according to Day and Richardson, ${ }^{35}$ drinking measures should be at least trimester specific. A major strength of this study was the assessment of intake at three time points covering several windows of exposure. Recent reviews have shown that many studies fail to account for timing of exposure, which is likely one of the causes of the contradictory evidence surrounding alcohol intake and birth outcomes. ${ }^{79} 10$

This study was designed for the assessment of caffeine intake and not alcohol consumption. However, the questionnaire was validated with reference to caffeine intake ${ }^{36}$ and is comparable to other methods used in the assessment of alcohol. Despite intakes being self-reported and thus presenting the issue of under-reporting, alcohol exposure was assessed prospectively in trimesters 1 and 2, reducing the potential for differential measurement (recall) bias. Ideally, alcohol intake should have been validated using a biomarker, but as yet, there are no biomarkers which can adequately assess low alcohol intakes and identify patterns of intake. ${ }^{37}$

Another limitation is the low sample size observed in the 3rd trimester. The original study of caffeine and birth outcomes planned to follow up women several weeks after delivery to investigate how their caffeine metabolism had returned to normal, using a caffeine challenge. This proposed data collection was expensive. To reduce costs without introducing selection bias, all cases (SGA and LBW infants) were recruited for postpartum follow-up, but only a sample of controls, taken to be the next two births that were not SGA or LBW. We found little difference between the controls who completed follow-up compared to those who did not, apart from the fact that women who stayed in the study were less likely to live in a deprived area (22\% compared to $29 \%$ in non-completers, data not shown).

Despite the limitations discussed, the potential risk to the fetus presented by even low maternal alcohol intakes prior to and during pregnancy warrants further investigation. Future studies should also take into account timing of exposure, including the period leading up to pregnancy. Maternal alcohol consumption usually decreases throughout pregnancy, as shown in our study, and therefore, averaging exposure measured at one time point in pregnancy to reflect exposure across the whole of pregnancy may obscure any true associations.

\section{CONCLUSION}

This analysis of prospectively collected data of a British cohort has demonstrated that low levels of maternal alcohol consumption, in particular in the first trimester, have a negative association with fetal growth and gestational age and greatly increase the odds of babies being born SGA and preterm. Pregnant women and women planning to become pregnant should be advised to abstain from drinking, as even those women who adhered to the UK guidelines of 1-2 units once or twice a week in the first trimester were at risk of having babies with reduced birth weight and born preterm when compared to mothers who abstained from alcohol.

\section{What is already known on this subject}

- Alcohol is a known teratogen.

- There is a lack of consensus in the evidence regarding the level and timing of maternal alcohol consumption during pregnancy that is considered to be safe.

- This lack of consensus is reflected in the different country-level policies regarding alcohol consumption during pregnancy.

\section{What this study adds}

- This study measured alcohol intake at four time points, before pregnancy and in trimesters 1,2 and 3 .

- The association with adverse birth outcomes was strongest in trimester 1, where there was a twofold increase in the odds of babies being born small for gestational age to mothers drinking more than 2 units/week compared to non-drinkers.

- A similar association was observed for preterm birth, where even women who adhered to the Department of Health guidance limiting alcohol to no more than 2 units per week were at risk of having babies born preterm compared to women who abstained from alcohol.

\section{Policy implications}

Public health messages about abstaining from alcohol when pregnant and planning to conceive need to be promoted.

Acknowledgements We would like to acknowledge the women participating in this study and the research midwifes for their invaluable contribution, Sinead Boylan for recruitment and data collection, Susan Shires for laboratory analysis of cotinine and caffeine levels, and James Thomas and Neil Hancock for database management. 
Contributors The CARE study was designed by and carried out under the leadership of JEC and NABS. CN conducted the statistical analysis with assistance from DCG and NAA and led the drafting of the manuscript. AWMH and KLMW carried out the laboratory investigations. All authors contributed to subsequent drafts of the manuscript and have read and approved the final manuscript.

Funding The CARE study was supported by a grant from the Food Standard Agency, UK (T01033). Camilla Nykjaer's PhD Studentship is jointly funded by the Medical Research Council (MR/K500914/1) and the Rank Prize Foundation.

\section{Competing interest None.}

Ethics approval Leeds West Local Research Ethics Committee approved this study (ref 03/054).

Provenance and peer review Not commissioned; externally peer reviewed.

Open Access This is an Open Access article distributed in accordance with the terms of the Creative Commons Attribution (CC BY 3.0) license, which permits others to distribute, remix, adapt and build upon this work, for commercial use, provided the original work is properly cited. See: http://creativecommons.org/ licenses/by/3.0/

\section{REFERENCES}

1 Lemoine $\mathrm{P}$, Borteyru $\mathrm{H}$, Menuet JC. Les enfants de parents alcooliques. Anomalies observees, a propos de 127 cas. Quest Medical 1968;21:476-82.

2 Ulleland CN. The offspring of alcoholic mothers. Ann N Y Acad SCi 1972;197:167-9.

3 Jacobson JL, Jacobson SW. Drinking moderately and pregnancy. Effects on child development. Alcohol Res Health 1999:23:25-30.

4 Spohr HLS, Steinhause HC. Alcohol, pregnancy and the developing child. Cambridge: Cambridge University Press, 1996.

5 Institute ILS. Overview of the health issues related to alcohol consumption. Belgium: Blackwell Science Ltd, 1999

6 Gray R, Henderson J. Report to the Department of Health-Review of the fetal effects of prenatal alcohol exposure. Oxford: National Perinatal Epidemiology Unit, 2006.

7 Henderson J, Gray R, Brocklehurst P. Systematic review of effects of low-moderate prenatal alcohol exposure on pregnancy outcome. BJOG 2007;114:243-52.

8 Henderson J, Kesmodel U, Gray R. Systematic review of the fetal effects of prenatal binge-drinking. J Epidemiol Community Health 2007:61:1069-73.

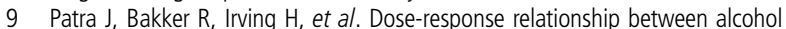
consumption before and during pregnancy and the risks of low birthweight, preterm birth and small for gestational age (SGA)-a systematic review and meta-analyses. BJOG 2011;118:1411-21.

10 O'Leary CM, Bower C. Guidelines for pregnancy: what's an acceptable risk, and how is the evidence (finally) shaping up? Drug Alcohol Rev 2012;31:170-83.

11 O'Leary CM, Heuzenroeder L, Elliott EJ, et al. A review of policies on alcohol use during pregnancy in Australia and other English-speaking countries, 2006. Med Aust 2007; 186:466-71.

12 American Congress of Obstetrics and Gynecologists. Alcohol and women. ACOG, 2011.

13 International Center for Alcohol Policies. International guidelines on drinking \& pregnancy. ICAP, 2009.
14 Department of Health. Pregnancy and alcohol. DH, 2008.

15 NICE. Antenatal care. NICE, 2010

16 Fat LN, Fuller E. Drinking patterns. Health Survey for England-2011, Health, social care and lifestyles. Health and Social Care Information Centre, 2011.

17 Health and Social Care information Centre. Infant feeding survey-2010. HSCIC, 2012

18 Rudd AO, Osborne S, Burl L, et al. The Morning After: A Cross Party Inquiry into Unplanned Pregnancy: 2020health.org, 2013.

19 British Medical Association. Alcohol misuse: tackling the UK epidemic. BMA, 2008

20 O'Keeffe JM, Daly G, Kearney PM, et al. Moderate alcohol consumption in early, middle and late pregnancy and small for gestational age, preterm birth and birth weight: a retrospective cohort study. Reprod Sci 2013;20:Suppl: 209A(F060).

21 Chiaffarino F, Parazzini $F$, Chatenoud $L$, et al. Alcohol drinking and risk of small for gestational age birth. Eur J Clin Nutr 2006;60:1062-6.

22 O'Leary CM, Nassar N, Kurinczuk JJ, et al. The effect of maternal alcohol consumption on fetal growth and preterm birth. BJOG 2009;116:390-400.

23 Parazzini F, Chatenoud L, Surace $M$, et al. Moderate alcohol drinking and risk of preterm birth. Eur J Clin Nutr 2003;57:1345-9.

24 CARE Study Group. Maternal caffeine intake during pregnancy and risk of fetal growth restriction: a large prospective observational study. BMJ 2008;337:a2332.

25 Cade JE, Burley VJ, Greenwood DC, U. K. Women's Cohort Study Steering Group. The UK Women's Cohort Study: comparison of vegetarians, fish-eaters and meat-eaters. Public Health Nutr 2004;7:871-8.

26 Gardosi J. Customized fetal growth standards: rationale and clinical application. Semin Perinatol 2004;28:33-40.

27 Binnie V, McHugh S, Macpherson L, et al. The validation of self-reported smoking status by analysing cotinine levels in stimulated and unstimulated saliva, serum and urine. Oral Diseases 2004;10:287-93.

28 Willet W. Nutritional epidemiology. 2nd edn. New York: Oxford University Press, 1998.

29 Meltzer HM, Brantsaeter AL, Ydersbond TA, et al. Methodological challenges when monitoring the diet of pregnant women in a large study: experiences from the Norwegian Mother and Child Cohort Study (MoBa). Matern Child Nutr 2008;4:14-27.

30 Centers for Disease Control and Prevention. Alcohol use among women who are pregnant or who might become pregnant-Unites States 2002. MMWR Morb Mortal Wkly Rep 2004;53:1178-81.

31 Feldman $\mathrm{HS}$, Jones KL, Lindsay $\mathrm{S}$, et al. Prenatal alcohol exposure patterns and alcohol-related birth defects and growth deficiencies: a prospective study. Alcohol Clin Exp Res 2012:36:670-6.

32 Shu XO, Hatch MC, Mills J, et al. Maternal smoking, alcohol drinking, caffeine consumption, and fetal growth: results from a prospective study. Epidemiology 1995;6:115-20.

33 Boniface $S$, Shelton N. How is alcohol consumption affected if we account for under-reporting? A hypothetical scenario. Eur J Public Health 2013;23:1076-81.

34 Jones KL. The effects of alcohol on fetal development. Birth Defect Research Part C: Embryo Today: Reviews 2011;93:3-11.

35 Day NL, Richardson GA. An analysis of the effects of prenatal alcohol exposure on growth: a teratologic model. American journal of medical genetics. Part C: Seminars in Medical Genetics 2004;127C:28-34.

36 Boylan SM, Cade JE, Kirk SF, et al. Assessing caffeine exposure in pregnant women Br J Nutr 2008; 100:875-82.

37 Bearer CF, Stoler JM, Cook JD, et al. Biomarkers of alcohol use in pregnancy. Alcohol Res Health 2004;28:38-43. 